\title{
The Improvement of Carbon Anode Performance Using Coupled Mixing
}

\author{
XIAO Chun ${ }^{1, a}$, ZHANG Hui ${ }^{1, b}$ \\ ${ }^{1}$ School of Materials and Civil Engineering, Gui Zhou Normal University ,Gui Yang \\ 550025,P.R.China \\ aemail:630914239@qq.com, bemail:1044979670@qq.com
}

Key words: coupling; impurity; carbon anode; performance

Abstract: Carbon anode is an important material of aluminum electrolysis, its performance directly affects the aluminum electrolytic consumption and the quality of the electrolytic aluminum. The control range of ingredients is determined by the meaning of mixing, the quality control point is determined by coupled theory of trace impurity elements ingredients, the quality standards of raw materials are explored from the change rule of impurity elements in calcinations and roasting. Through the implementation of these solutions, homogenization technology of the preparation of carbon anode can be guaranteed, the performances of the carbon anode are improved, in which the $\mathrm{CO}_{2}$ response residue are all above $90 \%$, the highest up to $95.13 \%$.

\section{Introduction}

In modern aluminium electrolytic production, pre-baked anode is known as the "heart" of aluminum electrolytic cell. It not only bears the current conduction for electrolysis, but also participates in electrochemical reaction of electrolytic cell, and therefore, the preparation of pre-baked anode carbon block is a key technology of electrolytic aluminium production. Pre-baked carbon anode preparation is a complex process, including collocation of all kinds of materials according to the proportion, calcining, crushing screening, kneading, vibration forming, roasting and assembly and each process affects the quality of anode carbon block ${ }^{[1]}$. For oxidation resistance performance of anode carbon block, it is often affected by the density of anode carbon block and chemical composition ${ }^{[2]}$. To output stable quality of high quality carbon anode, there are some technical challenges in the aluminium industry in China, including intensive study of carbon anode production process rules and related theory, using different quality of modified asphalt and petroleum coke, changeable process and production conditions at the scene. For coupled mixing homogenization technology, many researchers only get conclusions from mixing of petroleum coke, such as coupling of calcium and sodium, vanadium ${ }^{[3,4]}$, but they don't optimize the preparation of anode process from generalized coupling, and there is rare good application in practical production. In this paper, reaction residue $\mathrm{CO}_{2}$ of finished anode is increased up to $95.13 \%$, and the performance of the anode is improved through the discussion of the coupling in whole process of preparing anode preparation and the application of coupling.

\section{Coupled mixing technology in anode preparation process}

According to the preparation process of pre-baked anode, influences on performance of carbon anode can be obtained from trace impurities content in raw petroleum coke, trace impurity content in calcined coke, modified pitch and anode scrap, size distribution of calcined coke (polar residue, raw) in kneading material, usage ratio of all kinds of kneading materials. With application of their 
complementarities, the anode preparation process and the anode performance can be improved; this is the generalized coupled mixing technology of carbon anode production.

\section{Control point of quality in coupled mixing}

Mixing of raw petroleum coke

According to the chemical composition and complementary action of trace elements content of petroleum coke, some trace elements have the opposite effects on carbon anode performance, coupled with the reason that the performance of petroleum coke is often related to the origin place, so it is necessary to mix petroleum coke from different places. With the increase of imported crude oil, sulfur and vanadium content in petroleum coke is high in general, so it needs petroleum coke from the northeast refineries when mixing, to reduce mass fraction of sulfur and vanadium after mixed; Sulfur and vanadium content in petroleum coke are high in north China and east China, also are the calcium, iron content, so it needs petroleum coke from southern China with low calcium, iron content, to reduce calcium and iron content in the raw coke firstly, and then in the process of calcinations, desulfurized efficiency needs to be improved to guarantee certain sulfur content in petroleum coke to suppress the vanadium negative effects on the performance of carbon anode. Sulfur in petroleum coke after calcining and roasting can emerge $20 \% \sim 40 \%$, so according to the sulfur requirements of the carbon anode in the contract, the sum of several kinds of sulfur petroleum coke selected needs less than $70 \%$ of anode sulphur index.

For raw petroleum coke with high volatility and lots of powders, stable quality of calcined petrolem coke can be obtained by adding petroleum coke with coarse powder and low volatile, and maintaining the normal calcine temperature in calcination process.

The most significant impurities in petroleum coke resisting carbon dioxide and air oxidation are: calcium, vanadium, sodium, sulfur, nickel, iron and aluminum ${ }^{[5,6]}$. Sodium has the greatest effect in the activity of carbon anode in the air, and sulfur inhibits the oxidation reaction ${ }^{[6]}$; Sulfur with calcium are also complementary, if the content of trace impurities in petroleum coke are blended according to the Table 1 which is from Chinalco, the catalysis of calcium, vanadium and nickel to the air reactivity and carbon dioxide reactivity are inhibited. Petroleum coke homogenization technology of trace impurities as the key control point is implemented, and different species, different composition and different granularity of petroleum coke are mixed in flat out straight way, in accordance with control principle that the $\mathrm{S} \leq 2.5 \%$ (individual content $3.5 \%$ ), $\mathrm{S} / \mathrm{Ca}$ is $100 \sim 150, \mathrm{~S} / \mathrm{Na}$ is $100 \sim 150, \mathrm{~S} / \mathrm{V}$ is $70 \sim 100$, so the trace impurities are homogenized in the production of petroleum coke, also the quality of production materials in other aspects is guaranteed, which leads to improvement of the carbon anode $\mathrm{CO}_{2}$ reactivity residual, the air reactivity residual and the air permeability, and enhancement of the intensity of the anode and the electrical conductivity. Product performance comparison are shown in table 2. 
Table 1 Impurity content in petroleum coke [ppm]

\begin{tabular}{lll} 
& Mixed before & Mixed after \\
\hline Air permeability $/ \mathrm{nPm}$ & 2.66 & $<1.8$ \\
$\mathrm{CO}_{2}$ Reaction residue $/ \%$ & 58.78 & $>86$ \\
Air Reaction residue $/ \%$ & 62.84 & $>81$ \\
Apparent density $/ \mathrm{g} \cdot \mathrm{cm}^{3}$ & 1.53 & 1.58 \\
Resistivity $/ \mu \Omega \cdot \mathrm{m}$ & 53 & $<52$ \\
Compressive strength $/ \mathrm{Mpa}$ & 36.4 & $>38$ \\
\hline
\end{tabular}

Content of impurities, particle size and proportion coupling when mixing calcined coke and asphalt

According to the coking mechanism, firstly binder matrix is formed with powder and asphalt, blending caking matrix model like Fig. 1 is obtained in laboratory, and then the bond matrix stick all grade solid phase particles together. The blending ratio and conditions in laboratory are applied in follow-up experiments and industrial practice. Since the particle size of petroleum coke raw materials in Chinalco is small, it will be with high porosity, lots of powders, large ash and poor strength after calcined, and asphalt matrix and dry powders form accumulation after kneading, therefore, ingredients solution is improved as shown in table 3 , mixing of dry and wet material can obtain large density, small porosity kneading materials; Then through vibration molding, kneading materials form strong raw block in which large particles accumulate, middle particles fill and small particles continue to fill, as shown in Fig. 2.

Table 2. Ingredients Solution

\begin{tabular}{ccccccccccccc}
\hline Sample & $\mathrm{Si}$ & $\mathrm{Fe}$ & $\mathrm{Na}$ & $\mathrm{V}$ & $\mathrm{Al}$ & $\mathrm{Ca}$ & $\mathrm{Ti}$ & $\mathrm{Ni}$ & $\mathrm{P}$ & $\mathrm{Pb}$ & $\mathrm{Zn}$ & $\mathrm{S}(\%)$ \\
\hline 82301 & 220 & 140 & 26 & 300 & 140 & 250 & 11 & 210 & 24 & 4 & 9.6 & 3.2 \\
82302 & 23 & 59 & 22 & 300 & 24 & 260 & 5.5 & 250 & 4.8 & 0.7 & 5.1 & 2.28 \\
\hline
\end{tabular}

In the mixing process of wet and dry material, trace impurity content of asphalt is considered. Phosphorus and boron compounds in asphalt and aluminum fluoride can inhibit the oxidation reaction speed of dope focal, while sodium, lithium salts have strong catalytic oxidation reaction.

Based on the complementarity of these elements in the process of the binder using, the usage of different trace elements content of asphalt is consciously controlled, mass fraction of trace elements is controlled from the total amount of kneading material of asphalt and calcined coke. Coking temperature of bonding agent has a great influence on the activity of coking, therefore, kneading process must be strictly controlled to inhibit coking activity of pre-baked anode, making it consistent with petroleum coke and residual anode.

Finally when carbon block is in high temperature, asphalt will coke and combine the particles to form a solid strong overall. The test shows that air oxidation and carbon dioxide oxidation are reduced. 


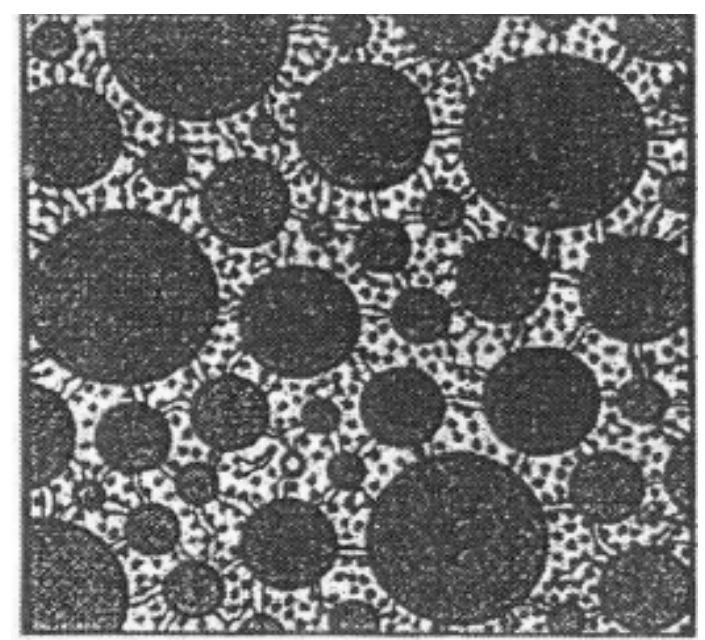

Fig.1 Bonding mechanism model of asphalt and carbon aggregate

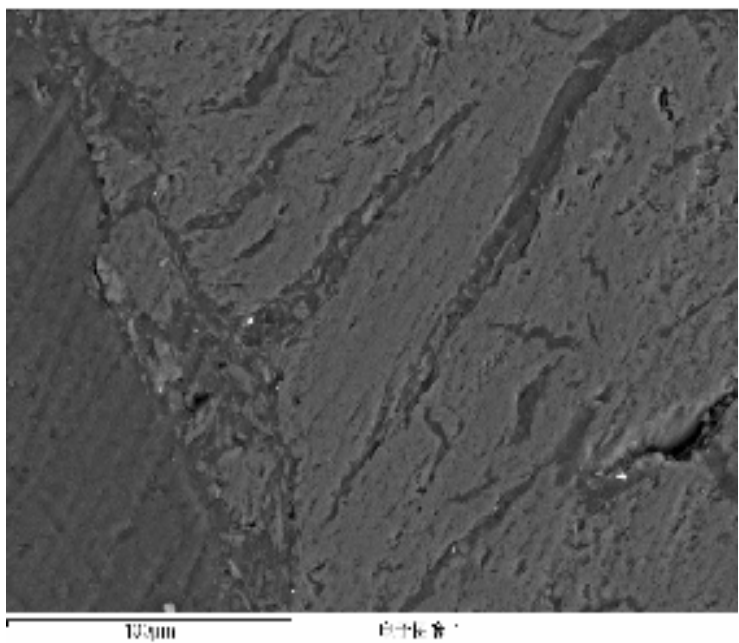

Fig.2 The raw block with matrix evenly infiltrated and soakaged with aggregate

Table 3 Dry and wet material proportioning schemes

\begin{tabular}{cccc}
\hline Raw material & Size range $[\mathrm{mm}]$ & Dry material Wt.[\%] & Purity \\
\hline Coke coarse & $8 \sim 6$ & 11.3 & $90 \%+$ \\
Coke grains & $6 \sim 3$ & 6.9 & $90 \%+$ \\
Coke fine grained & $3 \sim 0.15$ & 35.1 & $60 \sim 70 \%$ \\
Ball milling & $<0.15$ & 26.7 & $(70 \pm 5) \%$ \\
Residual very coarse & $8 \sim 3$ & 8.0 & $90 \%+$ \\
Residual fine griains & $<3$ & 12.0 & $60 \sim 70 \%$ \\
Asphalt & Making paste ratio/\% & $15.0 \pm 1$ & \\
\hline
\end{tabular}

\section{Impurity content in raw materials and anode performance}

The change of trace impurities of petroleum coke in calcined process

The calcination of petroleum coke is an important process in the preparation of carbon anode, and its main purpose is to eliminate moisture and volatile matter of raw material, and prompt gasification of monomer sulfur and decomposition of combined sulfur. Calcination is to improve the true density of raw material, mechanical strength, conductivity and antioxidant capacity ${ }^{[7]}$.

Within the normal calcining temperature scope of the petroleum coke, changes of all kinds of trace impurities of petroleum coke are showed in table 4. It shows that, except the S, the changes of various impurities are haphazard; the reason is that trace impurity content is low, the detection accuracy is not high, plus the amount of volatile evolution of petroleum coke material is out of proportion. The effect for the $\mathrm{S}$ removal under normal calcination temperature is not obvious; If we raise the temperature, the desulfurization rate is less than 20\%; The $\mathrm{S}$ content in petroleum coke is higher, the physical properties of calcined petrolem coke indicators will be worse, chemical properties will be significantly reduced; With the increase of calcination temperature, calcined petrolem coke decreased, while in range of $900 \sim 1200{ }^{\circ} \mathrm{C}$, the reduce amount of sulphur content is not much with the temperature raised, the desulfurization rate is similar. The resistivity of anode carbon block, the $\mathrm{CO}_{2}$ reactivity and air reactivity of the high content impurities are worse than the low content impurities. 
Table 4 The changes of trace impurities in process of calcination unit[\%]

\begin{tabular}{cccccccccccc}
\hline Sample & $\mathrm{S}$ & $\mathrm{Zn}$ & $\mathrm{Pb}$ & $\mathrm{Na}$ & $\mathrm{Ca}$ & $\mathrm{V}$ & $\mathrm{Si}$ & $\mathrm{Fe}$ & $\mathrm{Ni}$ & $\mathrm{P}$ & $\mathrm{Ti}$ \\
\hline $\mathrm{D} 150801$ & +1.56 & -20.80 & -97.50 & +111 & -32.00 & 13.33 & -18.18 & -14.28 & +4.76 & -83.33 & -33.64 \\
$\mathrm{D} 150802$ & -7.46 & +19.61 & -85.71 & +18.18 & +19.23 & -36.67 & +308 & 86.44 & 0 & 33.33 & +32.73 \\
$\mathrm{D} 150803$ & -7.06 & & & & & & & & & & \\
$\mathrm{D} 150804$ & -4.64 & & & & & & & & & & \\
\hline
\end{tabular}

The change of trace impurities in anode roasting process

Roasting is heat treatment of pressed carbon block under the condition of air isolation and medium protection, which changes the bonding agent to coke. Because asphalt in raw block tightly wraps in transition layer between the carbon particles, it becomes coke when in high temperature, and forms interface carbon grid layer in the intermediate product, which has the role of bypass and reinforcement. Roasting is a complex process with many chemical changes, and the key technology parameter of roasting process is roasting temperature. Under the normal roasting temperature, trace impurity in the anode carbon blocks changes according to the trend like table 5. The table 5 shows that the impurity content and quantity of modified pitch in calcined coke are difference, there is no rule for the trace impurity content of baked charcoal burner block, while the trace impurities change in roasting process is regular when burning raw block which is formed with modified pitch and calcined coke.

Table 5 The changes of trace impurities in roasting process [\%]

\begin{tabular}{ccccccccc}
\hline Sample & $\mathrm{S}$ & $\mathrm{Na}$ & $\mathrm{Ca}$ & $\mathrm{V}$ & $\mathrm{Si}$ & $\mathrm{Fe}$ & $\mathrm{Ni}$ & note \\
\hline $\mathrm{B} 150801$ & +7.38 & +7.14 & +7.29 & +7.14 & +7.53 & +7.53 & +7.29 & With the calcined coke as \\
$\mathrm{B} 150802$ & +27.49 & +746 & -3.22 & +21.05 & +240 & +382 & -28.00 & reference \\
$\mathrm{B} 150803$ & +5.85 & +391 & +23.53 & +2.94 & +5.56 & +275 & -27.27 & With anode as reference \\
\hline
\end{tabular}

Continuously adjust ingredients until to produce satisfactory carbon anode

Factory conducts repeated industrial experiments according to the ingredients laws fund in test to improve the performance of pre-baked anode, the specific products are shown in table 6 .

Table 6 Physical and chemical performance of carbon anode

\begin{tabular}{|c|c|c|c|c|c|c|}
\hline \multirow[b]{2}{*}{ Sample } & \multicolumn{5}{|c|}{ Physical property } & Chemical composition [ppm] \\
\hline & $\begin{array}{c}\text { Apparent } \\
\text { density } \\
{\left[\mathrm{g} / \mathrm{cm}^{3}\right]}\end{array}$ & $\begin{array}{c}\text { Ture } \\
\text { density } \\
{\left[\mathrm{g} / \mathrm{cm}^{3}\right]}\end{array}$ & $\begin{array}{l}\text { Resistivity } \\
{[\mu \Omega \text { ûm] }}\end{array}$ & $\begin{array}{l}\text { Residue } \\
\text { rate in } \\
\mathrm{CO}_{2}[\%]\end{array}$ & $\begin{array}{c}\text { Compressive } \\
\text { strength } \\
\text { [Mpa] }\end{array}$ & 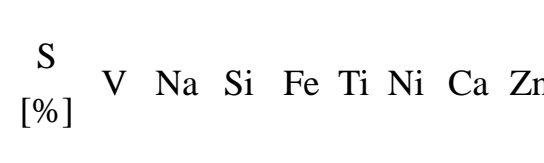 \\
\hline 01 & 1.56 & 2.05 & 56 & 95.13 & 43.5 & 2.142253442006452011935638 \\
\hline 02 & 1.58 & 2.04 & 52 & 91.84 & 50.00 & 1.96580244308601825025411 \\
\hline 03 & 1.55 & 2.05 & 55 & 90.47 & 42.1 & 2.08600163509701724028811 \\
\hline 04 & 1.56 & 2.05 & 54 & 93.14 & 43.5 & $2.01540 \quad 1630098018250302 \quad 9$ \\
\hline 05 & 1.59 & 2.06 & 51 & 90.03 & 48.3 & 2.694202203205301618030096 \\
\hline
\end{tabular}

Analysis of impurity elements in carbon anode effects on its performance, exploration of requirements for raw material 
In general, what lead to the most obvious effects on oxidation rate of the impurity in the carbon anode are sodium, nickel and vanadium. Sodium is a kind of extremely strong catalyst, which can dramatically increase the oxidation rate of pre-baked anode in the air or $\mathrm{CO}_{2}$ atmosphere, leading to increase consumption of pre-baked anode in use $^{[8,9]}$. Vanadium will accelerate oxidation of pre-baked anode, and dramatically reduce the conductivity of pre-baked anode. When vanadium content increases from 100 PPM to 200 PPM, pre-baked anode oxidation speed increases up to 0. $023 \mathrm{~g} / \mathrm{cm}^{2} \hat{\mathrm{h}}$; Under the same conditions, nickel increases oxidation rate up to $0.026 \mathrm{~g} / \mathrm{cm}^{2} \hat{\mathrm{h}}$. Sulfur affects the density of carbon anode, desulfurization of sulfur coke in anode roasting process can lead to very important phenomenon of micro porous, and greatly reduce the volume density, compared with low sulfur coke, the true density of high sulfur coke is much smaller. Other impurities like $\mathrm{P}_{2} \mathrm{O}_{5}, \mathrm{~V}_{2} \mathrm{O}_{5}$, and $\mathrm{Fe}_{2} \mathrm{O}_{3}$ all reduce the conductivity of carbon anode.

Based on the above materials impacts on the performance of the product, in combination with raw material, environment, and the control conditions of production technology, petroleum coke quality standard is proposed as shown in table 7.

Table 7 The quality standard of petro coke with carbon anode [ppm]

\begin{tabular}{|c|c|c|c|c|c|c|c|c|c|c|c|c|}
\hline Target & $\mathrm{S}[\%]$ & $\mathrm{V}$ & $\mathrm{Na}$ & $\mathrm{Ca}$ & $\mathrm{Ni}$ & $\mathrm{Si}$ & $\mathrm{Fe}$ & $\begin{array}{l}>8 \mathrm{~mm} \\
\text { Coke[\%] }\end{array}$ & $\begin{array}{c}<1 \mathrm{~mm} \\
\text { Coke[\%] }\end{array}$ & $\begin{array}{l}\text { Resistivity } \\
\text { of calcine } \\
{[\mu \Omega \text { ûm] }}\end{array}$ & $\begin{array}{l}\text { Air } \\
\text { dreactivity } \\
{[\%]}\end{array}$ & $\begin{array}{l}\mathrm{CO}_{2} \\
\text { reactivity } \\
{[\%]}\end{array}$ \\
\hline Level1 & $<1.5$ & $<80$ & $<80$ & $<100$ & $<200$ & $<150$ & $<150$ & $>60$ & $<10$ & $<450$ & $<0.25$ & $25 \sim 45$ \\
\hline Level2 & $1.5 \sim 2.5$ & $80 \sim 150$ & $80 \sim 150$ & $100 \sim 200$ & $<300$ & $150 \sim 300$ & $150 \sim 300$ & $50 \sim 60$ & $10 \sim 20$ & $450 \sim 500$ & $0.25 \sim 0.6$ & $45 \sim 60$ \\
\hline
\end{tabular}

\section{Conclusions}

Strengthening management can improve the accuracy of the ingredients

(1) Petroleum coke from different regions, different manufacturers, different quality should be partition stored, to prevent unqualified raw materials into the production process;

(2) The ingredients quality control point should be strictly managed, the impurity content of raw material, granularity, blending proportion should be kept under strict control, raw materials must be flat out straight into the process of petroleum to keep the coke quality to be stable.

Combined with the change of trace elements in petroleum coke calcine and anode roasting process, based on the quality promotion and consumption decrease in today's aluminum industry, quality standard of carbon anode used in the preparation of petroleum coke is proposed, providing a basis for high quality anode production.

With the coupled mixing techniques, the stable quality of calcine coke, anode and finished anode produced by petroleum coke used in production process can be guaranteed, and the performance is improved, the $\mathrm{CO}_{2}$ response residues are all above $90 \%$.

\section{Acknowledgements}

This work was financially supported by the Natural Science Foundation of Guizhou Province, Grant No. LKS[2012] (02). 


\section{References}

[1] Jiang Wenzhong. Carbon Technology [M]. Beijing: Metallurgical Industry Press, 2009,120-520.

[2] Chen kai-bin, Liu Feng-qin, Yang hong-jie etc. Shallow Theory of Aluminium with the Factors Influencing the Quality of Pre-baked Carbon Anode [J]. Journal of Carbon Technology, 2008, 27 (1) : 27 to 30 .

[3] Deng Songyun. Ball Milling of Aluminum in the Influence of Carbon Cnode Performance Research [D]. Central South University, 2010.

[4] Ren Yaojian. Anthracite Coal Production of Aluminum Electrolysis Carbon Anode Research [D]. China Mining University, 2009.

[5] He Lei. With the Application of New Process in the Production of Carbon Anode Aluminum [D]. Hunan University, 2010.

[6] Xu Yan, Li Gang, Jin-he Wang, etc. The impurity in the Pre-baked Anode Effect on the Performance of its [J]. Journal of aluminum magnesium communications: 2003, (2) : 34-38.

[7] Li Xue-jun, Zhang Yu-zhen, Cheng Xiang-lin, etc. In the process of Petroleum Coke Calcined Behavior Research [J]. Journal of Carbon Technology, 2008, 27 (1) : 4-7.

[8] Su Zi-wei, Luo Ying-tao, Zhao Lin, etc. By Using the Calcined Coke Prediction of Carbon Anode Carbon Dioxide Reactivity of the Trace Elements Discussed [G]. The Second International Aluminum with Carbon Technology Conference, 205-211

[9] Zhang Nian-bing, Zheng Huan Liu Wei etc. Vanadium Elements on the Influence of the Carbon Anode Reaction Activity [J]. Journal of Nonferrous Metal Engineering, 2013, 3 (6), 33-35. 